\title{
THE INFLUENCE OF NITRIDING ON THE GEOMETRIC ACCURACY OF PARTS OF SPECIAL TECHNOLOGY
}

\author{
${ }^{1}$ David DOBROCKÝ, 'Zdeněk POKORNÝ, 'Zbyněk STUDENÝ, 'Zdeněk JOSKA, \\ ${ }^{1}$ Jiří PROCHÁZKA, ${ }^{1} E$ mil SVOBODA \\ ${ }^{1}$ University of Defense in Brno, Brno, Czech Republic, EU, david.dobrocky@unob.cz
}

https://doi.org/10.37904/metal.2020.3568

\begin{abstract}
The current development of chemical-heat treatment technologies is aimed at increasing the utility properties of components and improving the quality of the produced surface. A prerequisite for a quality produced surface is the selection of a suitable method of surface machining before the application of chemical-heat treatment technology. Due to the requirements for functional areas of special technology, grinding is chosen in most cases. The present paper deals with the effect of nitriding in plasma and gas on the geometric accuracy of parts made of $42 \mathrm{CrMo} 4$ steel. This steel is widely used in special technology for the production of barrels, breech-block cases, ball screws and gears. On the ground steel samples, the 3D measurement on the coordinate measuring machine analyzed the change of dimensions after the application of nitriding in plasma and gas. Furthermore, the surface texture change was evaluated using 2D surface roughness parameters and 3D parameters of area. After nitriding in both plasma and gas, the dimensions increased by $0.034 \mathrm{~mm}$ in diameter. After the nitriding processes, the values of $2 \mathrm{D}$ and $3 \mathrm{D}$ surface roughness parameters decreased. $\mathrm{A}$ change in surface texture was observed when evaluating 3D parameters in both chemical-heat treatment processes. Increasing the dimensions and changing the texture of the surface affects the subsequent function of the components.
\end{abstract}

Keywords: Nitriding, grinding, dimension accuracy, surface texture, roughness

\section{INTRODUCTION}

The life of most components and tools is related to abrasion on the surface, the occurrence of fatigue cracks and corrosion effects. All these influences begin to apply mainly from the surface of components, and that is why it is crucial to influence the mechanical and other properties of the surface area [1,2].

When choosing the type of material, it is almost always necessary to compromise, as the required operating properties are often more or less contradictory. In addition to the optimal choice of material and its conventional heat treatment, traditional chemical-heat diffusion processes have become very important in recent years [3]. It is possible to consider as optimal especially such processes, the result of which are surface layers with good adhesion to the base material and during processing there are as minimal deformations of parts and tools as possible [4]. The most common requirement for properties after additional surface treatment is an increase in hardness. Of the plasma technologies, the greatest attention is given to chemical-heat treatment in a glow discharge, such as nitriding and carburizing. In the last decade, there has also been a significant development of PVD (physical) technologies for the preparation of coatings and their gradual introduction into industrial production. This rapid development has been fueled in particular by the fact that plasma technologies are opening up new avenues in creating layers of completely new properties $[5,6]$. 
While PVD technologies and their various modifications are used mainly on tools, chemical-heat treatment technology predominates in machine parts and processes the largest volume of products. Of great importance in these technologies is nitriding (classical in gas, plasma), which creates a hard surface layer, the purpose of which is $[7,8,9]$ :

- increase in corrosion resistance,

- $\quad$ increase of abrasion, wear resistance,

- increase of fatigue resistance under cycling loading.

Its formation is a diffusion process in which the atomic nitrogen formed by the thermal dissociation of ammonia penetrates the surface of the carbonated material. The dissociation process is essentially an ionization process which is largely intensified in a glow discharge or plasma environment. The electrostatic field present in plasma nitriding also accelerates the absorption of atomic nitrogen by the surface and its diffusion further into the material. Each of these purposes has different demands on the quality of the nitrided layer; suitable phase compositions are discussed e.g. in $[10,11]$.

For the intended use of the special technology, the machine parts must be designed in an appropriate manner (the design includes in particular the choice of material and determination of the geometry of the part) and manufactured by appropriate technological methods under appropriate conditions. An adequate level of geometric quality is essential for perfect function, which means that the part must have the desired shape and retain this shape for as long as possible. Highly exposed components of special technology require high geometric quality of functional surfaces. At present, high demands are placed on quality and its management and assurance (ISO 9000 standard). The geometric shape is conceived during the construction of the part; it is technologically treated and realized in the production process $[12,13]$.

To ensure the quality of the surface function, it is necessary to determine adequate accuracy (permissible inaccuracy, tolerance). Accuracy is generally understood as a measure of agreement between a desired and an actual value.

Each technological procedure leaves unevenness on the surface, which can negatively affect the required function of the surfaces [14]. These inequalities must be assessed in terms of their size and geometric character and confront the identified state with the requirements formulated in the technical documentation. The importance of a thorough assessment is especially for areas that will be in a direct functional relationship with other areas [15].

Important components of weapons, such as closing mechanisms or barrels, are made of low-alloy, noble $\mathrm{Cr}$ Mo steel 42CrMo4. The useful properties of this steel are increased mainly by nitriding [16]. At present, nitriding processes in both gas and plasma are widely used. Each of these processes has its pros and cons, of course the economic side also plays a role. Emphasis is placed especially on the functional surfaces of exposed components, which must have the required surface quality and geometric accuracy.

The presented article deals with the evaluation of the change in dimensional accuracy of ground samples made of $42 \mathrm{CrMo} 4$ steel and the change in surface texture after nitriding processes in gas and plasma. It is generally known that these processes cause a slight increase in size [17].

\section{EXPERIMENTAL METHODS}

\subsection{Production of experimental samples}

The experimental samples were made in the form of blocks measuring $90 \mathrm{~mm} \times 30 \mathrm{~mm} \times 20 \mathrm{~mm}$ (Figure 1). For each nitriding technology, 5 pieces of experimental samples were produced. The samples were made with a grinding allowance of $0.3 \mathrm{~mm}$. 


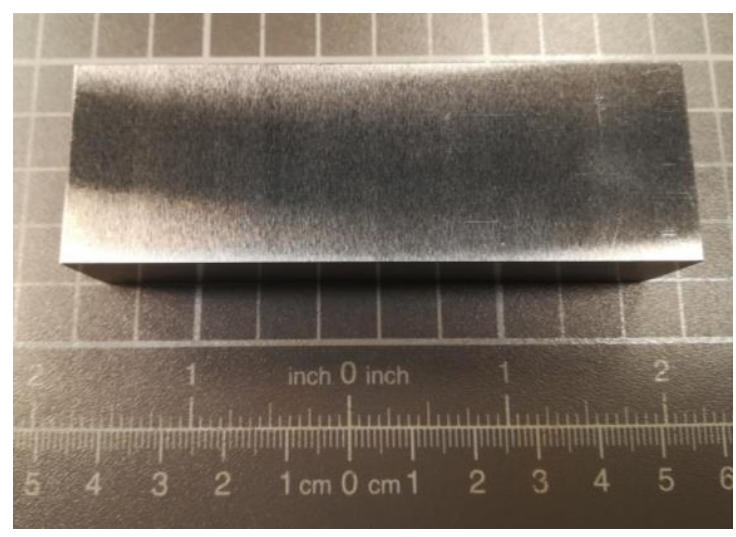

Figure 1 Experimental sample

\subsection{Chemical composition analysis of the evaluated steel}

The chemical composition of the analysed steel was performed using a Bruker-Quatron spark optical emission spectrometer Q4 Tasman. The results of the chemical composition of the analysed steel 42CrMo4 and their comparison with the standard are given in Table 1.

Table 1 Chemical composition of $42 \mathrm{CrMo} 2$ steela

\begin{tabular}{|c|c|c|c|c|c|c|c|}
\hline $\mathrm{C}$ & $\mathrm{Mn}$ & $\mathrm{Si}$ & $\mathrm{Cr}$ & $\mathrm{Ni}$ & $\mathrm{Mo}$ & $\mathrm{P}$ & $\mathrm{S}$ \\
\hline \multicolumn{7}{|c|}{ Standard } \\
\hline $0.38-0.45$ & $0.50-0.80$ & $0.17-0.37$ & $0.90-1.20$ & max. 0.50 & $0.15-0.30$ & max. 0.035 & max. 0.035 \\
\hline \multicolumn{7}{|c|}{ Q4 Tasman } \\
\hline 0.39 & 0.82 & 0.31 & 1.09 & 0.06 & 0.19 & 0.011 & 0.015 \\
\hline
\end{tabular}

\subsection{Heat treatment of experimental samples}

The heat treatment of the experimental samples consisted of normalization annealing, quenching and tempering in order to obtain a fine-grained sorbitic structure which has suitable mechanical properties. The heat treatment parameters are documented in Table 2.

Table 2 Parameters of heat treatment

\begin{tabular}{|c|c|c|}
\hline Normalization annealing & Quenching & Tempering \\
\hline $860{ }^{\circ} \mathrm{C} / 45 \mathrm{~min} /$ air & $840{ }^{\circ} \mathrm{C} / 45 \mathrm{~min} /$ water & $600{ }^{\circ} \mathrm{C} / 100 \mathrm{~min} /$ oil \\
\hline
\end{tabular}

\subsection{Machining of functional surfaces}

Evaluated surfaces of experimental samples after heat treatment were ground on a surface grinder BPH 300 with the aim to achieve surface roughness $\mathrm{Ra}=0.4 \mu \mathrm{m}-0.8 \mu \mathrm{m}$. The speed of the grinding wheel was set to $2400 \mathrm{rpm}$, the table shift was $10 \mathrm{~m} / \mathrm{min}$, the grinding wheel type 98A46J9V40 (J hardness). During grinding, the ground surfaces were cooled with Idazox HB 20 coolant. The concentration of coolant was 5\% (1:20).

\subsection{Chemical-heat treatment}

The parameters of the nitriding processes in plasma and gas were set in order to achieve a depth of the diffusion layer in the range of $0.25 \mathrm{~mm}-0.35 \mathrm{~mm}$, which corresponded to the setting of temperatures and process times. In addition, both nitriding processes required the suppression of a white nitride layer on the steel surface. Plasma nitriding was performed in a Rübig PN 100/180 device, nitriding in gas in a Nitrex 80/200 device. The process parameters are listed in Table 3. 
Table 3 Parameters of chemical-heat treatment

\begin{tabular}{|c|c|c|c|}
\hline Process & Temperature $\left[{ }^{\circ} \mathrm{C}\right]$ & Time $[$ hod] & Atmosphere \\
\hline Plasma nitriding & 520 & 14 & $1 \mathrm{~N}_{2}: 3 \mathrm{H}_{2}$ \\
\hline Nitriding in gas & 530 & 7 & $\mathrm{NH}_{3} / \mathrm{N}_{2} / \mathrm{H}_{2}$ \\
\hline
\end{tabular}

\subsection{Measuring of dimensions}

Measurements of dimensional change of experimental samples after chemical-heat treatment were performed on a 3D CNC coordinate machine Werth ScopeCheck $® S$ (Figure 2) and evaluated by WinWerth 8 software. Dimensional changes were evaluated by a touch sensor (ruby ball with a diameter of $3 \mathrm{~mm}$ ). The distances between the foreheads of the sample were measured, the surfaces of which were ground and the distance according to the drawing was prescribed at $90 \mathrm{~mm}$. The samples were measured first after heat treatment (thermal refining) and machining to the final dimensions and then after selected chemical-thermal treatment processes. The same measurement strategy was used for both measurements. All samples were measured 5 times, i.e. a total of 25 measurements of samples after heat treatment and 25 measurements after the selected process of chemical-thermal treatment. The measurement conditions are given in Table 4.

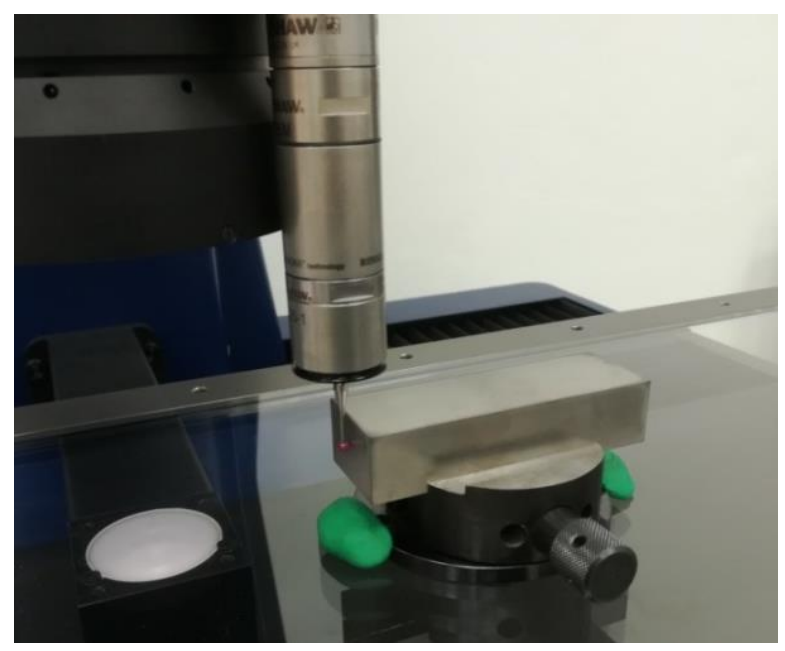

Figure 2 Fixing the sample on the table of a 3D CNC coordinate measuring machine

Table 4 Conditions for measuring the dimensional change

\begin{tabular}{|c|c|c|c|c|}
\hline $\begin{array}{c}\text { Measured area } \\
{[\mathrm{mm}]}\end{array}$ & $\begin{array}{c}\text { Number of scanned } \\
\text { points per area }\end{array}$ & Temperature $\left[{ }^{\circ} \mathrm{C}\right]$ & $\begin{array}{c}\text { Max. error } \mathrm{E} 1 \text { for } \mathrm{L} \\
=90 \mathrm{~mm}[\mu \mathrm{m}]\end{array}$ & $\begin{array}{c}\text { Uncertainty for } \\
\mathrm{L}=90 \mathrm{~mm}[\mathrm{~mm}]\end{array}$ \\
\hline $27 \times 17$ & 25 & $22 \pm 1$ & 3.25 & \pm 0.001 \\
\hline
\end{tabular}

\subsection{Measuring of surface texture}

The surface texture was measured on the ground surfaces of the experimental samples, always in the middle part of the machined surface of the sample. The surface texture parameters were measured by the non-contact method with a Talysurf CCl Lite coherent correlation interferometer. The obtained data were analyzed using MountainLab Premium 8 software. The conditions for measuring the surface texture are documented in Table 5.

The surface texture was evaluated by $2 \mathrm{D}$ roughness height parameters and $3 \mathrm{D}$ parameters of area. From the roughness parameters $\mathrm{Ra}, \mathrm{Rq}, \mathrm{Rz}$ and $\mathrm{Rt}$ were selected, from the 3D parameters were selected their equivalents Sa, Sq, Sz and St. The parameter names are listed in Table 6. 
Table 5 Conditions for measuring the surface texture of experimental samples

\begin{tabular}{|c|c|c|c|c|c|}
\hline $\begin{array}{c}\text { Evaluated surface } \\
\text { (3D) }\end{array}$ & $\begin{array}{c}\text { Evaluated } \\
\text { length (2D) }\end{array}$ & Cut-off & Filtration & $\begin{array}{c}\text { Number of } \\
\text { scanned points on } \\
\text { the evaluated } \\
\text { surface }\end{array}$ & $\begin{array}{c}\text { Number of } \\
\text { scanned } \\
\text { roughness } \\
\text { profiles }\end{array}$ \\
\hline $1,5 \mathrm{~mm} \times 1,5 \mathrm{~mm}$ & $4 \mathrm{~mm}$ & $0.8 \mathrm{~mm}$ & Gauss & $1800 \times 1800$ & 5 \\
\hline
\end{tabular}

Table 6 Measured parameters of surface texture

\begin{tabular}{|c|c|l|}
\hline Parameter & Unit & \multicolumn{1}{c|}{ The full name of the parameter } \\
\hline$R a$ & $\mu m$ & Arithmetic Mean Deviation of the roughness profile \\
\hline$R q$ & $\mu m$ & Root-Mean-Square (RMS) Deviation of the roughness profile \\
\hline$R z$ & $\mu m$ & Maximum Height of roughness profile \\
\hline$R t$ & $\mu m$ & Total Height of roughness profile \\
\hline$S a$ & $\mu m$ & Arithmetic Mean Deviation \\
\hline$S q$ & $\mu m$ & Root-Mean-Square Mean Deviation \\
\hline$S z$ & $\mu m$ & Total Point Height \\
\hline$S t$ & $\mu m$ & Total Height \\
\hline
\end{tabular}

\section{RESULTS AND DISCUSSION}

\subsection{Metallographic analysis}

Metallographic analysis of experimental samples was performed after chemical-thermal treatment, using an inverted opto-digital metallographic microscope Olympus DSX500. The microstructure of steel after thermal refining consisted of tempered martensite and sorbite (Figure 3-a). Plasma nitriding led to the formation of a tempered martensite structure, which towards the core of the material turns into tempered martensite and sorbitol (Figure 3-b). The diffusion layer became visible by etching the samples. A very thin continuous white layer of nitrides formed on the steel surface. The structure of tempered martensite and sorbite was formed in the surface layer after the gas nitriding process (Figure 3-c). Even in this case, the diffusion layer is visible after etching. Furthermore, a uniform, thick, white layer of nitrides was formed on the steel surface.

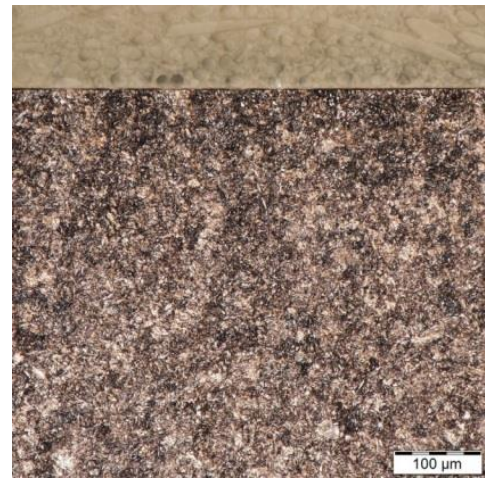

a)

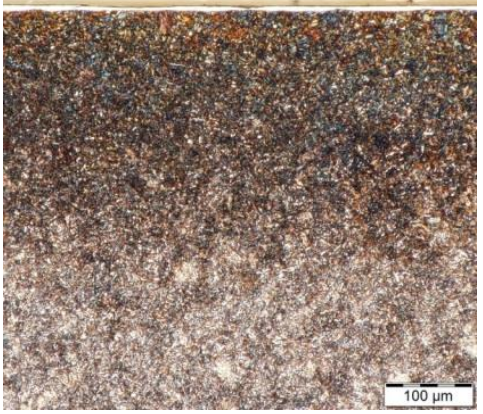

b)

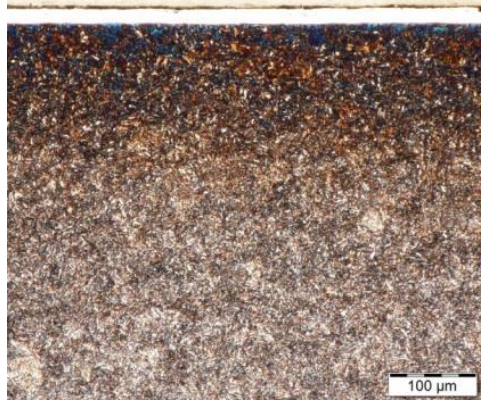

c)

Figure 3 Structure of $42 \mathrm{CrMo} 4$ steel after heat treatment a), nitriding in plasma b) and nitriding in gas $\mathrm{c}$ ), magnified 500x, etched NITAL 5\%

The depth of the diffusion layer and the thickness of the white layer of nitrides were measured together with the evaluation of the metallography. The depths of the diffusion layers were measured using microhardness 
curves on an automated Leco LM247AT microhardness tester, with a load of $100 \mathrm{~g}$ (HV0.1). 5 microhardness curves were always measured. The thicknesses of the white layers were measured optically at a magnification of $1000 x$, in five places each. Furthermore, the surface hardness was measured on an instrumented Zwick ZHU 2.5 hardness tester, with a load of $10 \mathrm{~kg}$ (HV10). All 5 samples from each nitriding process were measured, always at five different locations. The results of the above measurements are summarized in Table 7; the table shows the mean values.

Table 7 Results of measuring the depth of the diffusion layer, the thickness of the white layer and the surface hardness

\begin{tabular}{|c|c|c|c|}
\hline Process & $\begin{array}{c}\text { Depth of the diffusion layer } \\
{[\mathrm{mm}]}\end{array}$ & $\begin{array}{c}\text { Thickness of the white } \\
\text { layer }[\mu \mathrm{m}]\end{array}$ & Surface hardness HV10 \\
\hline Plasma nitriding & 0.319 & 6.4 & 665 \\
\hline Nitriding in gas & 0.224 & 18.4 & 705 \\
\hline
\end{tabular}

\subsection{Change of dimensions after chemical-heat treatment}

After the process of chemical-thermal treatment, there was an increase in the dimensions of experimental samples, resp. their length. The values of the increase in the dimensions of the experimental samples, given in Table 8, express the mean value of the increase from the 25 measurements. The table also shows the change in the degree of accuracy IT of experimental samples according to EN ISO 286-1.

Table 8 Values of increase in dimensions of experimental samples after nitriding processes

\begin{tabular}{|c|c|c|}
\hline Process & Dimension increase $[\mathrm{mm}]$ & $\begin{array}{c}\text { Change in the degree of } \\
\text { accuracy of IT }\end{array}$ \\
\hline Plasma nitriding & $0.032 \pm 0.001$ & from 8 to 9 \\
\hline Nitriding in gas & $0.036 \pm 0.002$ & from 8 to 9 \\
\hline
\end{tabular}

From the results of dimensional change measurements, it is evident that after nitriding in plasma and gas, the dimensions of the experimental samples increased by values ranging from $0.032 \mathrm{~mm}$ to $0.036 \mathrm{~mm}$. Increasing the size deteriorated the accuracy class by one degree.

\subsection{Change of surface texture after chemical-heat treatment}

The change of selected area parameters and surface roughness parameters is shown in Table 9.

Table 9 Results of surface and area roughness measurements

\begin{tabular}{|c|c|c|c|c|c|c|}
\hline \multirow{2}{*}{ Parameter } & \multirow{2}{*}{ Unit } & Ground surface & \multicolumn{2}{|c|}{ Plasma nitriding } & \multicolumn{2}{c|}{ Nitriding in gas } \\
\cline { 4 - 7 } & & $\begin{array}{c}\text { Measured } \\
\text { value }\end{array}$ & Decrease & $\begin{array}{c}\text { Measured } \\
\text { value }\end{array}$ & Decrease \\
\hline $\mathrm{Ra}$ & $\mu \mathrm{m}$ & $0.96 \pm 0.06$ & $0.87 \pm 0.06$ & -0.09 & $0.87 \pm 0.11$ & -0.09 \\
\hline $\mathrm{Rq}$ & $\mu \mathrm{m}$ & $1.30 \pm 0.05$ & $1.18 \pm 0.09$ & -0.12 & $1.16 \pm 0.17$ & -0.14 \\
\hline $\mathrm{Rz}$ & $\mu \mathrm{m}$ & $7.06 \pm 0.18$ & $6.26 \pm 0.35$ & -0.80 & $6.43 \pm 0.59$ & -0.63 \\
\hline $\mathrm{Rt}$ & $\mu \mathrm{m}$ & $7.16 \pm 0.18$ & $6.38 \pm 0.27$ & -0.78 & $6.52 \pm 0.59$ & -0.14 \\
\hline $\mathrm{Sa}$ & $\mu \mathrm{m}$ & $0.92 \pm 0.09$ & $0.81 \pm 0.08$ & -0.11 & $0.83 \pm 0.10$ & -0.09 \\
\hline $\mathrm{Sq}$ & $\mu \mathrm{m}$ & $1.23 \pm 0.11$ & $1.08 \pm 0.05$ & -0.15 & $1.11 \pm 0.03$ & -0.12 \\
\hline $\mathrm{Sz}$ & $\mu \mathrm{m}$ & $7.08 \pm 0.16$ & $6.53 \pm 0.21$ & -0.55 & $6.94 \pm 0.16$ & -0.14 \\
\hline $\mathrm{St}$ & $\mu \mathrm{m}$ & $7.64 \pm 0.18$ & $6.69 \pm 0.17$ & -0.95 & $7.09 \pm 0.08$ & -0.55 \\
\hline
\end{tabular}


It is clear from the results that after both nitriding processes there was a decrease in the evaluated area parameters and surface roughness parameters. The largest decrease was recorded for the peak parameters $\mathrm{Rz}$, Rt and Sz, St. However, in general, it can be said that there was no significant change in the roughness parameters of ground surfaces and surfaces after nitriding processes.

The morphology of the surfaces is shown in Figure 4. Images of the surfaces were taken on an Olympus DSX500 opto-digital metallographic microscope. The images show a change in the surface, traces of the grinding tool are visible on the ground surface, parallel to the grinding direction, dark deeper furrows and light grey peaks can be noticed. Dark furrows (valleys) are not visible after the nitriding processes; this corresponds to their filling and this result in a reduction of the resulting surface roughness. The 3D texture of individual surfaces has a similar morphology. After the nitriding processes, the peaks of the protrusions were slightly rounded.
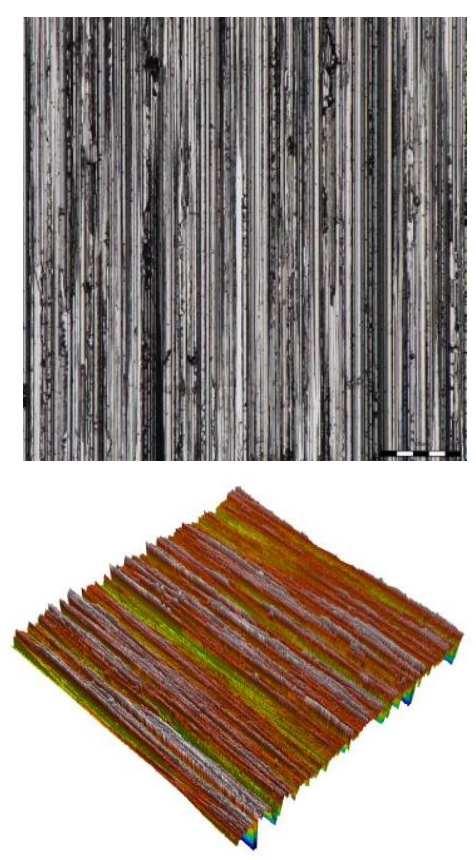

Ground
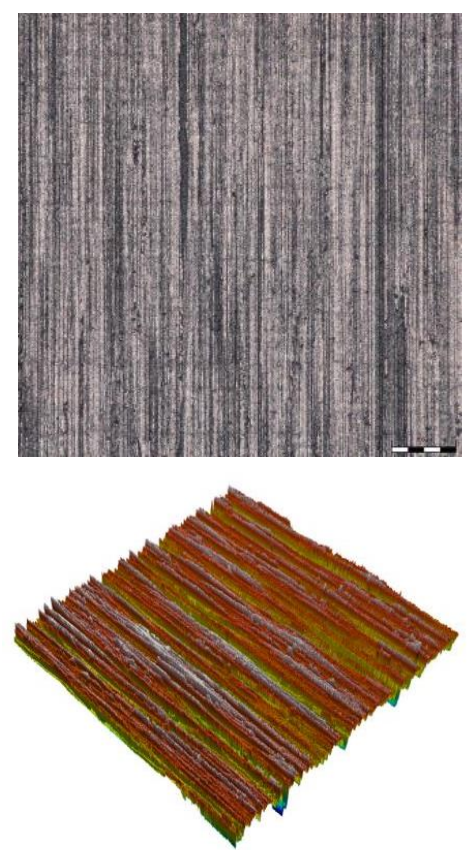

Plasma nitrided
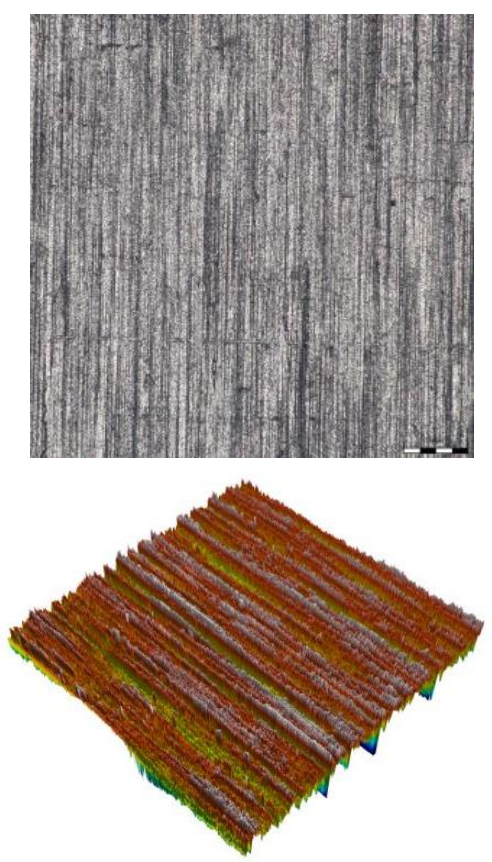

Nitrided in gas

Figure 4 Morphology of evaluated surfaces (magnified 500x) and their 3D texture

Furthermore, the maximum and mean depths of the furrows on the surface were measured (Figure 5). The results are documented in Table 10. The results confirm that the nitriding processes lead to the filling of the furrows created by grinding process and thus reduce their depth.

a)

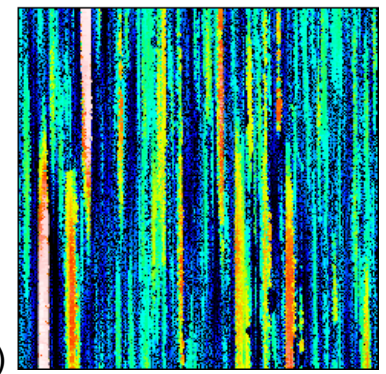

b)

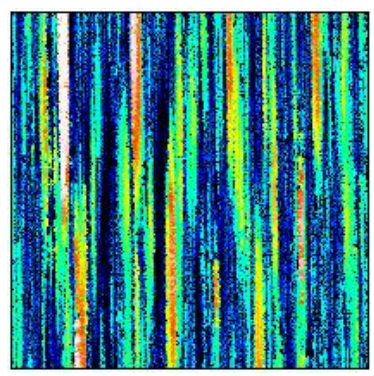

c)

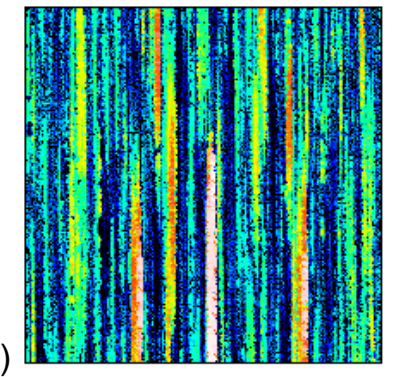

Figure 5 Imaging of furrows on the ground surface a), the surface after nitriding in plasma b) and nitriding in gas $\mathrm{c}$ ) 
Table 10 Results of evaluation of the depth of furrows of the analysed surfaces

\begin{tabular}{|c|c|c|}
\hline Process & Maximum depth of furrows $[\mu \mathrm{m}]$ & Mean depth of furrows $[\mu \mathrm{m}]$ \\
\hline Ground & 6.734 & 1.735 \\
\hline Plasma nitriding & 5.861 & 1.527 \\
\hline Nitriding in gas & 6.497 & 1.662 \\
\hline
\end{tabular}

The above conclusion can also be substantiated by evaluating the volume parameters (Figure 6) of the surface, which is shown in Table 11. After the nitriding processes, the volume of the peaks increased slightly, but the volume of the core material decreased. Furthermore, the unfilled volume of the core was reduced, i.e. the valleys formed by grinding process were filled. This fact is confirmed by the reduction of the unfilled volume of the valleys Vvv.

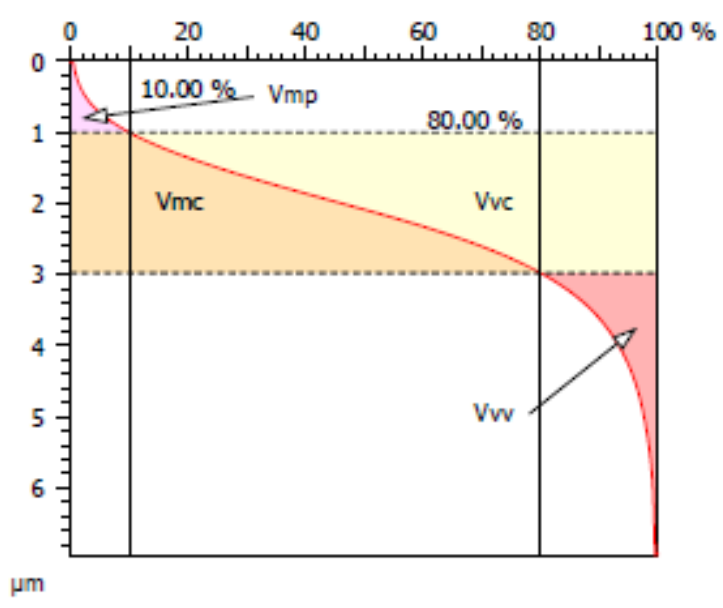

Figure 6 Volume parameters with Abbott curve of sample after nitiridng in gas

Table 11 Results of volume parameters of the surfaces

\begin{tabular}{|c|c|c|c|c|c|}
\hline Parameter & Unit & Name & Ground & Plasma nitriding & Nitriding in gas \\
\hline $\mathrm{Vmp}$ & $\mathrm{mm}^{3} / \mathrm{mm}^{2}$ & $\begin{array}{c}\text { Peak material } \\
\text { volume }\end{array}$ & $3.316 \cdot 10^{-5}$ & $3.401 \cdot 10^{-5}$ & $3.496 \cdot 10^{-5}$ \\
\hline $\mathrm{Vmc}$ & $\mathrm{mm}^{3} / \mathrm{mm}^{2}$ & $\begin{array}{c}\text { Core material } \\
\text { volume }\end{array}$ & $9.857 \cdot 10^{-4}$ & $8.688 \cdot 10^{-4}$ & $8.981 \cdot 10^{-4}$ \\
\hline $\mathrm{Vvc}$ & $\mathrm{mm}^{3} / \mathrm{mm}^{2}$ & $\begin{array}{c}\text { Core void } \\
\text { volume }\end{array}$ & $1.158 \cdot 10^{-3}$ & $1.010 \cdot 10^{-3}$ & $1.080 \cdot 10^{-3}$ \\
\hline $\mathrm{Vvv}$ & $\mathrm{mm}^{3} / \mathrm{mm}^{2}$ & $\begin{array}{c}\text { Valley void } \\
\text { volume }\end{array}$ & $2.182 \cdot 10^{-4}$ & $1.885 \cdot 10^{-4}$ & $1.865 \cdot 10^{-4}$ \\
\hline
\end{tabular}

\section{CONCLUSION}

The presented article deals with the influence of nitriding on the dimensional accuracy of components of a special technology. Experimental samples made of $42 \mathrm{CrMo} 4$ steel, which is widely used in the armaments industry, especially in the manufacture of weapons, were selected for evaluation. After heat treatment, the experimental samples were ground to the required dimensional accuracy and surface quality. The process of plasma nitriding and nitriding in gas led to an increase in the dimensions of the samples by $0.032 \mathrm{~mm}$ and $0.036 \mathrm{~mm}$. As the sample size increased, the IT accuracy class deteriorated from 8 to 9 . Analysis of the surface texture by selected $2 \mathrm{D}$ and $3 \mathrm{D}$ parameters revealed a reduction in the surface roughness of the nitrided samples, compared to the ground surfaces. This trend was also confirmed by a change in the morphology of 
the surface, from which it is clear that after the nitriding processes, the valleys on the steel surface were filled. This conclusion was confirmed by evaluating the depth of the furrows and the volume parameters of the surface. After the nitriding processes, the furrows on the steel surface created by grinding were partly filled. As the sample dimensions have increased, it is assumed that the original ground surface gains volume outwards from the component after nitriding processes. This process is most intense in the valleys of the surface, but also takes place on the peaks. The obtained results can be used in the production of special equipment components. The components will produce in the lower limit of tolerance and the nitriding process will not only increase the size and reach the middle limit of tolerance, but also improve the quality of the surface. However, the disadvantage of this process is that it is affected by the chemical composition of the steel and only some steels behave in this way. By modifying the nitriding parameters, the parameters of the functional surfaces could be changed according to their use in operation. However, the disadvantage of nitriding processes remains the change in dimensions, which leads to a deterioration in the geometric accuracy of the components.

\section{ACKNOWLEDGEMENTS}

The work presented in this paper has been supported by the specific research project 2020 ,SV20216" at the Department of Mechanical Engineering, University of Defense in Brno and the Project for the Development of the Organization „DZRO K201“.

\section{REFERENCES}

[1] JIANG, P., BLAWERT, C., BOHLEN, J., ZHELUDKEVICH, M.L. Corrosion fatigue behaviour and mechanical integrity of an extruded Mg4Zn0.2Sn alloy. Journal of Materials Science \& Technology, vol. 59, 2020, pp. 107116.

[2] BOUZAKIS, E., ARVANITIDIS, A., KAZELIS, F., MALIARIS, G., MICHAILIDIS, N. Comparison of Additively Manufactured vs. Conventional Maraging Steel in Corrosion-Fatigue Performance after various treatments. Procedia CIRP, vol. 87, 2020, pp. 469-473.

[3] POKORNY, Z., HRUBY, V., STRANSKY, K., KADLEC, J. Properties of plasma nitride layers in deep cavities. In METAL 2011: $20^{\text {th }}$ International Conference on Metallurgy and Materials. Ostrava: TANGER, 2011, pp. 786-791.

[4] JAROŠ, A., SEDLÁK, J., JAŠEK, P. The Investigation of the Influence of Modern Coating Applied to the Cutting Inserts During Machining. Manufacturing Technology, vol. 19, 2019, no. 4, pp. 589-595.

[5] GRONOSTAJSKI, Z., KASZUBA, M., WIDOMSKI, P., SMOLIK, J., ZIEMBA, J., HAWRYLUK, M. Analysis of wear mechanisms of hot forging tools protected with hybrid layers performed by nitriding and PVD coatings depositions. Wear, vol. 420-421, 2019, pp. 269-280.

[6] DURST, O., ELLERMEIER, J., BERGER, C. Influence of plasma-nitriding and surface roughness on the wear and corrosion resistance of thin films (PVD/PECVD). Surface and Coatings Technology, vol. 203, 2008, no. 5-7, pp. 848-854.

[7] KOSTUREK, R., ŚNIEZEK, L., TORZEWSKI, J., WACHOWSKI, M. Low Cycle Fatigue Properties of Sc-Modified AA2519-T62 Extrusion. Materials, vol. 13, 2020, no. 220, pp. 1-12.

[8] KUSMIČ, D., FALTEJSEK, P., ČECH, O. Corrosion Resistance of Plasma Nitrided Ferritic Steels X12Cr17. ECS Transactions, vol. 95, 2020, pp. 427-435.

[9] STUDENÝ, Z., ŠURLÁKOVÁ, M., CHLEBINOVÁ, L. Fatigue Fracture Roughness Character After Plasma Nitriding Process. Metal 2017: 26th International Conference on Metallurgy and Materials. Ostrava: TANGER,, 2017, pp. 1092-1097.

[10] JASINSKI, J.J., FRACZEK, T., KURPASKA, L., LUBAS, M., SITARZ, M. Investigation of nitrogen transport in active screen plasma nitriding process - Uphill diffusion effect. Journal of Molecular Structure, vol. 1164, 2018, pp. 37-44. 
[11] POKORNÝ, Z., DOBROCKÝ, D., KALDEC, J., STUDENÝ, Z. Influence of alloying elements on gas nitriding process of high-stressed machine parts of weapons. Kovove Materialy-Metallic Materials, vol. 56, 2018, no. 2, pp. 97-103.

[12] KIM, M-K., WANG, Q., YOON, S., SOHN, H. A mirror-aided laser scanning system for geometric quality inspection of side surfaces of precast concrete elements. Measurement, vol. 141, 2019, pp. 420-428.

[13] PANG, X., ZHANG, Y., WANG, CH., CHEN, Z., TANG, N., CHEN, B. Effect of cutting parameters on cutting force and surface quality in cutting of articular cartilage. Procedia CIRP, vol. 89, 2020, pp. 116-121.

[14] JANKOVYCH, R., HAMMER, M., HARCARIK, M. Bore quality of shotgun barrel blanks. MM Science Journal, 2018, pp. 728-730.

[15] KLANICA, O., SVOBODA, E., BARTOŠíK, P. The Surface Quality of the Deep Hole Drilling. Littera Scripta, vol. 6, 2013, no. 2, pp. 162-171.

[16] DOAN, T.V., KUSMIČ, D., POSPÍCHAL, M. Surface Treatment Technologies for Wear Resistance of 42CrMo4 Steel. Manufacturing Technology, vol. 15, 2015, no. 3, pp. 303-307.

[17] SINGH, G.P., ALPHONSA, J., BARHAI, P.K., RAYJADA, P.A., RAOLE, P.M., MUKHERJEE, S. Effect of surface roughness on the properties of the layer formed on AISI 304 stainless steel after plasma nitiridng. Surface and Coatings Technology, vol. 200, 2006, pp. 5807-5811. 